\title{
Commentary: An important contribution to pediatric cardiac surgery in low- and middle-income countries
}

\author{
Emile Bacha, MD
}

\footnotetext{
From the Division of Cardiac, Thoracic, and Vascular Surgery, New York-Presbyterian/Columbia University Medical Center, New York, NY; and Pediatric and Congenital Cardiac Surgery, Morgan Stanley Children's Hospital and Komansky Weill-Cornell, New York, NY.

Disclosures: Author has nothing to disclose with regard to commercial support.

Received for publication Sept 25, 2019; revisions received Sept 25, 2019; accepted for publication Sept 25, 2019; available ahead of print Oct 25, 2019.

Address for reprints: Emile Bacha, MD, Division of Cardiac, Thoracic, and Vascular Surgery, New York-Presbyterian/Columbia University Medical Center, Pediatric and Congenital Cardiac Surgery, Morgan Stanley Children's Hospital and Komansky Weill-Cornell, 3959 Broadway, CHN-274, New York, NY 10032 (E-mail: eb2709@cumc.columbia.edu).

J Thorac Cardiovasc Surg 2020;159:250

$0022-5223 / \$ 36.00$

Copyright $($ c 2019 by The American Association for Thoracic Surgery

https://doi.org/10.1016/j.jtcvs.2019.09.115
}

For those pediatric heart surgeons like myself, practicing in high-income countries, atrial switch operations such as the Mustard procedure have become rarely performed procedures. They are typically done in the setting of the doubleswitch procedure for corrected transposition of the great arteries (TGA), or in the setting of even rarer malformations, such as isolated ventricular inversion. The majority of children born with D-TGA, however, are born in developing countries. Most of them die early as the result of lack of diagnosis or access to pediatric heart surgery. Those who survive are the "late presenters," and these form the basis for the study in this issue of the Journal by Hosny and colleagues ${ }^{1}$ from the Aswan Heart Center in Upper Egypt.

Hosny and colleagues ${ }^{1}$ report on an astounding 634 patients presenting with TGA at their center during a 5.5year period, or roughly 9 patients per month. Of those, 101 underwent a Mustard operation, with the last 86 undergoing operation with their modified technique. Immediate and midterm results were outstanding, especially given the local resource limitations. One has to pause and take in those numbers. To my knowledge, this is by far the largest contemporary series of atrial switches reported. This experience literally revives this operation and reestablishes it as a rightful central component of treatment for TGA late presenters. The technical modifications of the Mustard operation revolve mainly around maximizing atrial wall muscle in the baffles by minimizing the length of the initial atriotomy and moving it more posterior (thereby leaving more atrial wall muscle available for the systemic baffle); resecting the limbus and any atrial septum, including the Eustachian valve; unroofing the coronary sinus; and incorporating the right atrial appendage into the superior vena caval channel. Although some of these maneuvers are well known, the thought process of maximizing atrial functions as a reservoir and a contractile chamber, and not will tell. these patients better.

\section{References} 241-9.

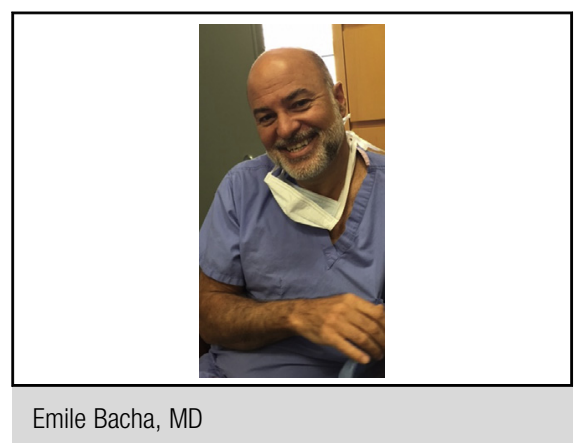

Central Message

A large contemporary experience with the Mustard atrial switch for transposition of the great arteries is reported. A technical modification to maximize atrial baffle function is described.

See Article page 241

just as a stiff and inert conduit, is worthy and thoughtful. Hosny and colleagues ${ }^{1}$ present imaging and physiologic data to show that the "morphodynamic" function of the heart, a concept promoted and explored by Dr Yacoub for a long time, ${ }^{2,3}$ is improved. Whether these modifications result in "better survival and quality of life," only time

Although more details on the management of specific patients, such as those with large ventricular septal defects or severe pulmonary hypertension, or on the role of "palliative" Mustard operations would have been interesting, there is no doubt that this group has established itself as thought leaders at the forefront of pediatric cardiac surgery in low- and middle-income countries. It will be important to continue these studies under the most rigorous conditions possible, given local resource limitations. Without a doubt, the information in this article will also help other centers in underdeveloped countries to care for

1. Hosny H, Sedky Y, Romeih S, Simry W, Afifi A, Elsawy A, et al. Revival and modification of the Mustard operation. J Thorac Cardiovasc Surg. 2020;159:

2. Kilner PJ, Yang GZ, Wilkes AJ, Mojiaddin RH, Firmin DN, Yacoub MH. Asymmetric redirection of flow through the heart. Nature. 2000;404:759-61.

3. Yacoub MH, Kilner PJ, Birks EJ, Misfeld M. The aortic outflow and root: a tale of dynamism and crosstalk. Ann Thorac Surg. 1999;68(3 Suppl):S37-43. 